\title{
Efficient Driving Forces to CMMI Development using Dynamic Capabilities
}

\author{
Maruthi Rohit Ayyagari \\ College of Business, University of Dallas \\ Texas, USA
}

\begin{abstract}
The innovation of new technologies and dynamic marketing environments led software organizations to adopt standards and best practices. The main objectives of these organization are to improve engineering and development, management of service delivery, and supplier management processes. The Capability Maturity Model Integration (CMMI) provides models for acquiring products (CMMI-ACQ), models for quality services (CMMI-SRV), and models for development (CMMI-DEV). The CMMI follows a set of stages known as the CMMI levels from one to five that determine an organization maturity level. Therefore, as the organization raises its maturity level to a higher level, it increases productivity, Return on Investments (ROI), and resource utilization. However, as a reference model, CMMI does not provide tools with the dynamic behavior of a competitive environment; therefore, organizations strive to enhance their market shares. This paper proposes to integrate the dynamic capability model with the CMMI; accordingly, the proposed model adapts and empowers the organization's resources competitively. This paper intends to add dynamic capability components as part of the CMMI levels four and five. The proposed framework was validated using the System Usability Scale (SUS) model. Results showed that the model is applicable and useful to enhance organization competence.
\end{abstract}

\section{General Terms}

Software Engineering, process improvement, development

\section{Keywords}

CMMI, dynamic capabilities,software usability scaling (SUS)

\section{INTRODUCTION}

Software quality aims to increase productivity, minimize rework, and reduces regression tests [1], [2]. The Capability Maturity Model Integration (CMMI) implementation increases organization efficiency, productivity, and enhance customer satisfaction and organization profit [3]. Several studies have reported the advantages of adopting the CMMI model [3]-[6]. According to a study of 30 organizations that implemented CMMI, the medians from the sample showed $34 \%$ reduction in cost, $50 \%$ reduction in schedule, $61 \%$ increase in productivity, $48 \%$ increase in product quality, and $14 \%$ increase in customer satisfaction [7].

Figure 1 shows the CMMI four categories of interleaved process areas. The organization process management empowers project management that employs engineering activities to develop and improve new CMMI process management practices. The support category guides and supports the engineering activities to measure and assist baseline improvements. As a result, managers make decisions based on measurements and analysis of the current situation. However, implementing software process improvement models (i.e., CMMI) are hinged on achieving business results [8], [9].
Moreover, CMMI improvements are affected by external environmental factors. The microenvironment consists of the factors that directly impact the operation of a company which may have control over[10]. The microenvironment includes factors of suppliers, financiers, customers, marketing intermediaries, and public perceptions. On the other hand, the macro environment factors[11] affect business, in which a company does not directly control the market; therefore, the success of an organization depends on its ability to adapt. The macroenvironment includes factors of economic, political, technical, sociocultural, legal, and environmental considerations. The scope of these factors is outside the scope of this paper; however, the goal of the paper is to find a solution that adapts CMMI implementation to reduce dynamic environment issues; therefore, an organization gets resilience to such factors[12][13].

The CMMI best practices reference has three divisions: CMMI for Acquisition (CMMI-ACQ), CMMI for Services (CMMISRV), and CMMI for Development (CMMI-DEV). The CMMI-ACQ model guides applying CMMI best practices in an acquiring organization. The best practices in the model focus on activities for initiating and managing the acquisition of products or services to meet the requirements of customers and end users. The CMMI-SRV is an integrated set of best practices that improve an organization capability to competently and successfully deliver quality service offerings that meet market and customer needs. CMMI-DEV is an integrated set of best practices that improve an organization's capability to develop quality products and services that meet the needs of customers and end users.

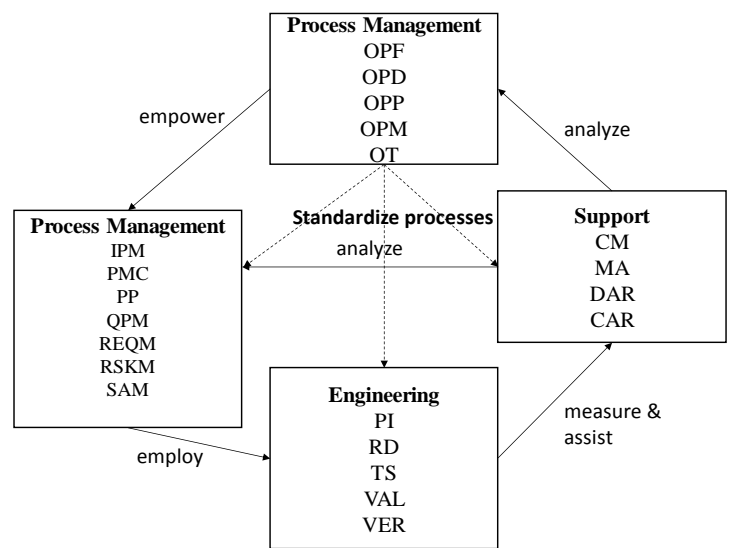

Fig.1. CMMI categories of process areas category. 


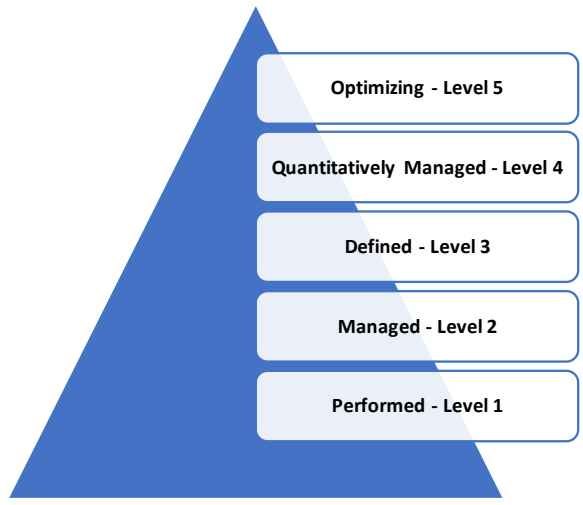

Fig. 2. CMMI 1.3 staged view

Since software organizations are subject to a dynamically changing environment and influential factors[14], the software development and supporting management process in CMMI should be agile to handle unplanned changes. Although agile methodologies reduce the time and impact of changes, it does not take into consideration the external environmental factors[15]. The CMMI model is considered a complex reference model [16] that does provide tools to deal with the dynamic capabilities of an organization. Therefore, this paper proposes a new framework that includes dynamic capabilities as part of the CMMI stages.

Dynamic capabilities proposed by [17], [18] is an organizational concept that emphasizes the capability to integrate, shape, and reconfigure internal and external competencies to address rapidly changing environments. Because every organization is dissimilar, there is no comprehensive set of rules for an organization to build dynamic capabilities, particularly in today's volatile, uncertain, complex, and ambiguous business environments. The software improvement is not an exception as software vendors need to integrate marketing with software development process and standards.

While dynamic capabilities can stay outside CMMI, the integration of both models ensures granularity of CMMI process to adapt according to the environment. Therefore, CMMI becomes mature enough to modify and change to the current organization situation. The objective of this paper is to propose an extension to the CMMI by adopting dynamic capabilities.

The proposed framework is composed of CMMI and the dynamic capabilities that reside in level 4 and level 5 of CMMI. The new components are customized for CMMI and are integrated with the whole organization strategic management capabilities. While measuring and controlling process, a CMMI developer may sense new opportunities to enhance the current process based on the new environment change of resource, technology, and support. Then sensed features and opportunities are analyzed in the seize step when new development or refinement of a process is scheduled. At the last step, the processes are transformed to accompany new changes

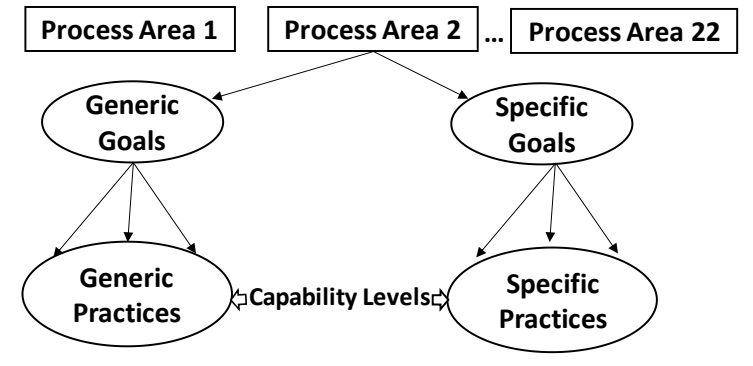

Fig. 3. CMMI continuous view

The remaining parts of the paper are organized as follows. Section two summarizes a background of CMMI and dynamic capabilities. Section three summarizes related work. Section four illustrates the proposed framework, while Section five shows the evaluates and discussion of the proposed model. Section six summarizes conclusions and future research.

\section{BACKGROUND}

\subsection{CMMI}

The CMMI was initially developed by the Software Engineering Institute(SEI) to undertake the software engineering profession maturing [6] based on the development of its predecessor, the Capability Maturity Model (CMM). The CMMI is a collection of best practice processes in product engineering and engineering management. The model gives freedom to implementers as it describes what not how, leaving a room of customization by adopters. The CMMI V1.3 has three divisions; the CMMI for Services (CMMI-SRV), the CMMI for Acquisition (CMMI-ACQ), and the CMMI for Development (CMMI-DEV). Both CMMI-DEV v1.3 and CMMI-ACQ v1.3 identify 22 process areas, whereas CMMISRV v1.3 identifies 24 process areas most of them are similar. A process area(PA) is "a cluster of related practices in an area that, when implemented collectively, satisfies a set of goals considered important for improving that area." $[6$, p. 23]

The most common view of the CMMI is a series of stages of maturity from one to five as shown in Figure 2. while the second view is concerned with the process areas that must resolve the company needs to be shown in Figure 3. In the first view, the five levels from one to five embodies an organizational plateau of the overall capability of the organization. Each level has a predefined set of assigned processes for cohesive implementations and results. At level one, the organization practices are ad hoc; therefore, there is no PAs at this level. Level two (managed), have practices of project management and product support practices that convert requirements to accepted products. Level three (defined), has an organized process as described in standards and the organization measures. Level four (quantitatively managed), has a continually improved process through iterative and incremental technologies. The last level establishes the finetuning of organizational processes and practices. An organization strives to target the highest level based on current constraints and environmental factors.

Although there are several attempts to simplify the implementation of CMMI [19], the CMMI does not provide dynamic capabilities; it remains limited to micro and macro environmental factors. Table 1 summarizes the needed process areas for this paper from level 3,4 and level 5 of the CMMI. 
Table 1. Summary of functional process areas in dynamic capabilities.

\begin{tabular}{|c|c|c|}
\hline Process Area & Description & Level \\
\hline Risk Management (RSKM) & $\begin{array}{l}\text { The purpose of RSKM is to identify potential problems before they occur so that } \\
\text { risk-handling activities can be planned and invoked as needed across the life of } \\
\text { the product }\end{array}$ & 3 \\
\hline Service Continuity (SCON) & $\begin{array}{l}\text { The purpose of SCON is to establish and maintain plans to ensure continuity of } \\
\text { services }\end{array}$ & 3 \\
\hline $\begin{array}{l}\text { Incident Resolution and } \\
\text { Prevention (IRP) }\end{array}$ & $\begin{array}{l}\text { The purpose of IRP is to ensure timely and effective } \\
\text { resolution of service incidents and prevention of service incidents as appropriate. }\end{array}$ & 3 \\
\hline $\begin{array}{c}\text { Strategic Service } \\
\text { Management (STSM) }\end{array}$ & $\begin{array}{l}\text { The purpose of STSM is to establish and maintain standard services in concert } \\
\text { with strategic needs and plans. }\end{array}$ & 3 \\
\hline $\begin{array}{l}\text { Organizational Process } \\
\text { Performance (OPP) }\end{array}$ & $\begin{array}{l}\text { The purpose of OPP is to establish and maintain a quantitative understanding of } \\
\text { the performance of selected processes in the organization's set of standard } \\
\text { processes; it aims to support achieving quality and process performance } \\
\text { objectives and to provide process performance data, baselines, and models to } \\
\text { manage the organization's projects quantitatively. }\end{array}$ & 4 \\
\hline $\begin{array}{l}\text { Quantitative Project } \\
\text { Management (QPM) }\end{array}$ & $\begin{array}{l}\text { The purpose of QPM is to quantitatively manage the project to achieve the } \\
\text { project's established quality and process performance objectives }\end{array}$ & 4 \\
\hline $\begin{array}{l}\text { Organizational Performance } \\
\text { Management (OPM) }\end{array}$ & $\begin{array}{l}\text { The purpose of OPM is to proactively manage the organization's performance to } \\
\text { meet its business objectives }\end{array}$ & 5 \\
\hline $\begin{array}{l}\text { Causal Analysis and } \\
\text { Resolution (CAR) }\end{array}$ & $\begin{array}{l}\text { The purpose of CAR is to identify causes of selected outcomes and take action to } \\
\text { improve process performance. }\end{array}$ & 5 \\
\hline
\end{tabular}

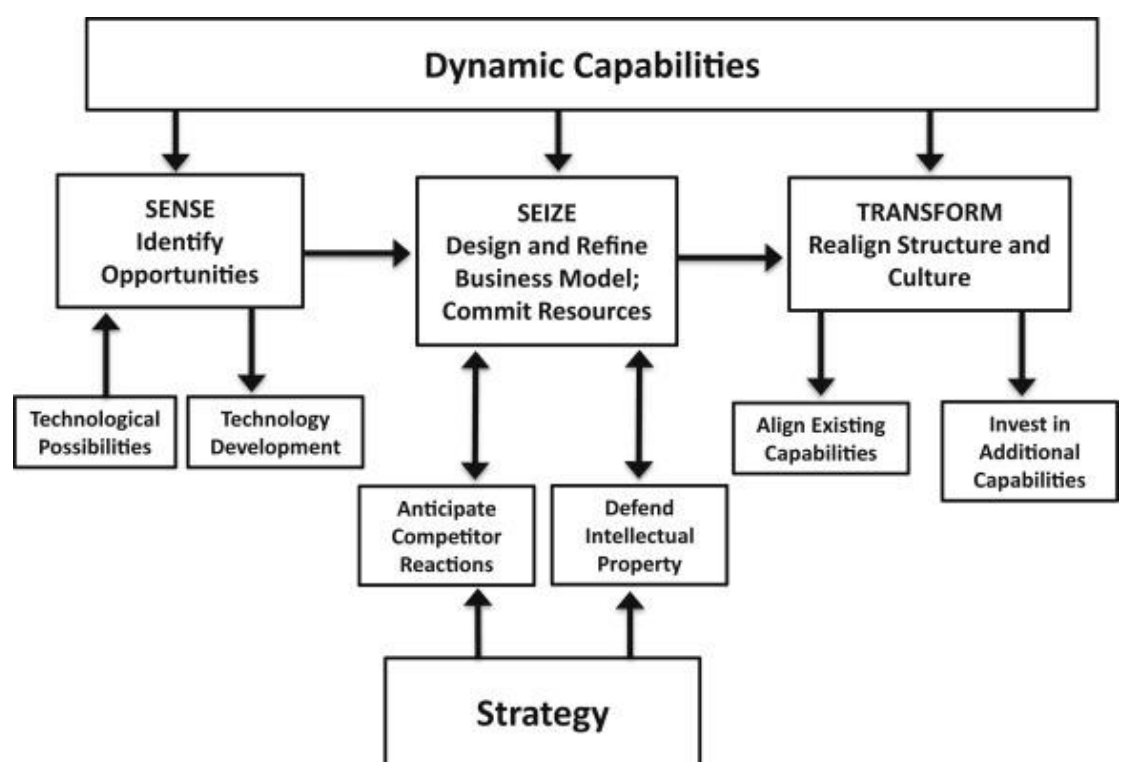

Fig. 4. Simplified schema of dynamic capabilities, business models, and strategy.

\subsection{Dynamic Capabilities}

Today's rapidly changing world can be challenging for many organizations. They need to meet the expectations of their customers, develop a strong brand identity, and be able to adapt quickly to radical shifts within software development. Software firms need to address new user needs that are hard to anticipate. Therefore, to meet their goals simultaneously, they aim to develop competitive dynamic capabilities. The dynamic capabilities concept emphasizes the capacity to integrate build and reconfigure internal and external competencies to address rapidly changing environments. Apple and IBM are considered excellent examples of dynamic capabilities. Their dynamic strategies and advanced technologically empowered them to grow and evolve.

Figure 4 shows Teece's new concept of dynamic capabilities[20] that ensures business corporate agility. The model consists of three main components: a sense that identifies opportunities and threats of technology, seize opportunities using resource and business models and transform apprehended opportunities by investing in new capabilities. 


\section{RELATED WORK}

\subsection{Dynamic Capabilities and CMMI Enhancements}

The dynamic capabilities are related to the assumed operational competencies, which refer to the current operations of an organization [21]. Such capabilities are essential in particular industries, predominantly for senior managers who set directions for their organizations [22]. The new dynamic capabilities framework of Web 2.0 focuses on the firm's ability to orchestrate and reconfigure externally sourced competences [21] rapidly.

There has been a great deal of related work that integrates CMMI with other components to enhance CMMI and provide a flexible and productive system. Agile best practices were integrated with CMMI level 5 [23]. Moreover, the CMMI was also combined with SCRUM[24] and with a Spiral model[19] for better user experience. In many organizations, CMMI is part of the underlying integrated systems [25]-[27]. Furthermore, the CMMI was extended for simulation systems engineering [28]. Although CMMI 2.0 has an improved value and reliability and is considered easy to use, it does not directly provide tools for dynamic capabilities.

\subsection{System Usability Scale}

The System Usability Scale (SUS) model [29] provides a quick, reliable tool for measuring the usability of products and services, applications, and websites. It consists of a 10-item questionnaire with Likert responses scale. The SUS model becomes a standard with more than 6000 citations according to Google citations. The SUS is simple and can be applied to small sample sizes.

At the end of the 10-question survey, the SUS is calculated based on a simple formula: subtract one from the odd question answers, subtract the value of the even question answers from 5 . Then add up the total score and multiply it by 2.5 . A result is a number on a scale of $1-100$. While it is not a percentage, it gives a clear way to understand the score; 100 is excellent user experience, equivalent to an " $\mathrm{A}$ "; 68 is considered average, a " $\mathrm{C}$ " grade; Anything below 68 is considered well below average, an "F..."[29]

\section{PROPOSED FRAMEWORK}

Since the CMMI level four and level five are mature and are considered a direction for the future of improvements, this paper proposes to integrate new dynamic capabilities components within these levels. The new components are customized for

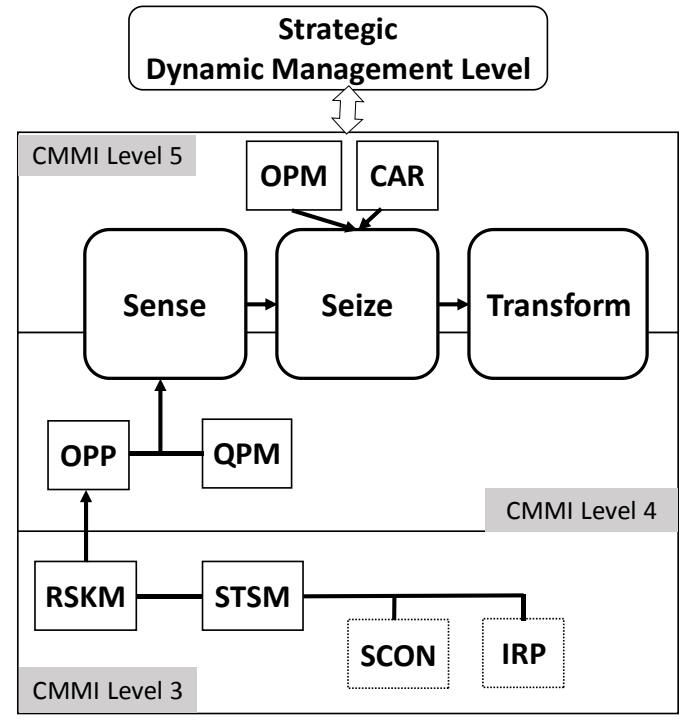

Fig.5. Proposed Model.

CMMI and are integrated with the whole organization strategic management. Figure 5 depicts the proposed framework. The sensing step identifies technological possibilities and developments using input from the Organizational Process Performance (OPP), the Organizational Performance Management (OPM), the Causal Analysis and Resolution (CAR), and the Risk Management (RSKM) process areas. The OPP process area provides performance data and baselines to sense potential deviation from originally established processes while the OPM process area allows to proactively manage an organization's performance to meet its business objectives. The CAR and the RSKM allow to manage and control issues and risks of any outcome of the processes. Given any outcome of an improved process, if an issue occurs, or if the risk is imposed within the improvement, then it should be mitigated to allow the sensing process to accumulate improvements.

Once an organization seizes a possible positive or negative change of process improvement within the context of the environment, the organization should carry out a resolution for adverse impacts and provide a recommendation for a positive impact of a change. The seize step utilizes the CAR and OPM process areas where the CAR allows taking proper action while the OPM process area allows the seizing process and organization future

The transform step carries out actions based on previous seized opportunities. The organization should align existing resources and capabilities to strategic objectives to maximize benefits. They could also invest in new capabilities to assure they remain in the market within the current level of CMMI. The transform step triggers the organization process assets management and provides lessons learned from the transformation.

\section{EVALUATION AND DISCUSSION}

This section runs the System Usability Scale (SUS) questionnaire to quantify the usability of the proposed model using ten experts. The SUS has a ten-item questionnaire that was adopted and modified to reflect issues related to the proposed model. The new ten-item questionnaire is shown in Table 2, with total ratings from participants for each question. Since the proposed model is not yet implemented, this paper modifies the questions to imply that the model has already been implemented. 
Table 2. Modified SUS assessed by ten business experts.

\begin{tabular}{|c|c|c|}
\hline Serial & Questionnaire & Total \\
\hline 1 & I think that I would like to use the proposed model frequently once implemented. & 38 \\
\hline 2 & I found the proposed model unnecessarily complex. & 24 \\
\hline 3 & I thought the proposed model was easy to use if process areas are detailed. & 35 \\
\hline 4 & I think that I would need the support of a technical person to be able to use the proposed model. & 18 \\
\hline 5 & I found the various functions in the proposed model were well integrated. & 31 \\
\hline 6 & I thought there was too much inconsistency in the proposed model. & 23 \\
\hline 7 & I would imagine that most people would learn to use the proposed model very quickly. & 39 \\
\hline 8 & I found the proposed model very cumbersome to use. & 19 \\
\hline 9 & I will feel very confident using the proposed model once implemented. & 37 \\
\hline 10 & I needed to learn a lot of things before I could get going with the proposed model. & 38 \\
\hline & Total (Even) & 101 \\
\hline & Total (Odd) & 180 \\
\hline
\end{tabular}

Table 3. Participants SUS scores.

\begin{tabular}{|c|c|}
\hline Participant & SUS Score \\
\hline $\mathrm{p} 1$ & 62.5 \\
\hline $\mathrm{p} 2$ & 72.5 \\
\hline $\mathrm{p} 3$ & 62.5 \\
\hline $\mathrm{p} 4$ & 75.0 \\
\hline $\mathrm{p} 5$ & 70.0 \\
\hline $\mathrm{p} 6$ & 72.5 \\
\hline $\mathrm{p} 7$ & 67.5 \\
\hline $\mathrm{p} 8$ & 77.5 \\
\hline $\mathrm{p} 9$ & 72.5 \\
\hline $\mathrm{p} 10$ & 65.0 \\
\hline
\end{tabular}

The Calculation of SUS figures was carried out using SUS guidelines. For every odd-numbered question, subtract one from the score. For every even-numbered question, subtract the scores from 5. Practically the application of this formula is carried out for each question and each question, then the average between all participants is calculated. Therefore, Table 2 reports a score of 68.5 usability score, which is considered the "Okay" acceptable model. The participants of SUS ratings, as shown in Table 2, shows that the scores of each participant are within the distribution with a standard deviation of 5.2.

The four significant steps of dynamic capabilities are illustrated stepwise to provide feedback at the previously proposed model.

1. Learning: during the first step of sensing, learning allows critical staff members and executives to analyze their workouts leading healthy interactions that cause the practical approaches of problemsolving.

2. Acquiring new assets: during the seizing step, acquiring new assets allows obtaining new assets by integrating technological factors and external activities with partnerships.

3. Transforming assets: while shaping an opportunity, transforming assets reconfigure the firm's current asset structure to attain the rapid internal and external transformation.

4. Co-specialization: during the transformation, cospecialization deduces a better combination of human resources with physical assets and intellectual properties for better value

Furthermore, this paper has applied another experiment to verify the proposed model. The proposed model was illustrated to a CMMI appraisal expert and two senior business managers. They could discuss and refine the model as needed. As a result, the CMMI appraisal expert admires the ideas that address the incompleteness of CMMI. However, business experts were not able to find how the proposed model will be executed.

Although the proposed model is providing a solution for dynamic changes, one drawback of the proposed model was that adopters will need support form technical team as the model is still conceptual, and no details of how to implement it. Also, experts pointed out that they need to learn more, as they need to understand two different domains, the CMMI and the dynamic capabilities.

\section{CONCLUSION}

This paper proposed an approach that integrates the CMMI model with dynamic capabilities. The approach integrates the dynamic capabilities as part of the CMMI level 5 using process areas from level 3,4, and 5. The Organizational Process Performance(OPP) establish the quantitative performance of selected processes which enable dynamic capabilities to sense environmental factors that affect current improvement in the CMMI. Using the Organizational Performance Management (OPM) and Causal Analysis and Resolution (CAR) process areas, along with input from the sensed opportunities, the seize step (of dynamic capabilities) designs and refines alternatives of improvements. As a result, the dynamic capabilities transform the structure and culture of the organization to maximize capacity and profit. The proposed model was 
validated using System Usability Scaling (SUS) with ten business experts. Results showed that the model is acceptable with "Okay" category. In the future, the author will expand the model with detailed processes.

\section{REFERENCES}

[1] I. Atoum, C. H. Bong, and N. Kulathuramaiyer, "Towards Resolving Software Quality-in-Use Measurement Challenges," Journal of Emerging Trends in Computing and Information Sciences, vol. 5, no. 11. pp. 877-885, 2014.

[2] I. Atoum, "A Novel Framework for Measuring Software Quality-in-use based on Semantic Similarity and Sentiment Analysis of Software Reviews," J. King Saud Univ. - Comput. Inf. Sci., p. , 2018.

[3] J. Samalikova, R. J. Kusters, J. J. M. Trienekens, and A. J. M. M. Weijters, "Process mining support for Capability Maturity Model Integration-based software process assessment, in principle and in practice," J. Softw. Evol. Process, vol. 26, no. 7, pp. 714-728, 2014.

[4] A. G. A. Saeed, R. S. Afgun Usmani, H. Akram, S. M. Saqlain, "The Impact of Capability Maturity Model Integration on Return on Investment in IT Industry: An Exploratory Case Study,” Eng. Technol. Appl. Sci. Res., vol. 7, no. 6, pp. 2189-2193, 2017.

[5] D. Chevers, "Software Process Improvement: Awarness, Use, and Benefits in Canadian Software Development Firms," Rev. Adm. Empres., vol. 57, no. 2, pp. 170-177, Apr. 2017.

[6] Software Engineering Institute, "CMMI for Development, Version 1.3," Carnegie Mellon University, 2010.

[7] R. W. Reitzig, D. R. Goldenson, D. Gibson, and M. R. Cavanaugh, "Calculating CMMI-Based ROI: Why, When, What, and How?," in 19th Annual SEPG Conference, 2007.

[8] C. Ebert, "Technical controlling and software process improvement," J. Syst. Softw., vol. 46, no. 1, pp. 25-39, Apr. 1999.

[9] S. Bayona, J. A. Calvo-Manzano, and T. San Feliu, "Critical Success Factors in Software Process Improvement: A Systematic Review," in Software Process Improvement and Capability Determination, 2012, pp. 1-12.

[10] F. Testa, N. M. Gusmerottia, F. Corsini, E. Passetti, and F. Iraldo, "Factors affecting environmental management by small and micro firms: The importance of entrepreneurs' attitudes and environmental investment," Corp. Soc. Responsib. Environ. Manag., vol. 23, no. 6, pp. 373-385, 2016.

[11] A. Wibowo and H. Wilhelm Alfen, "Identifying macroenvironmental critical success factors and key areas for improvement to promote public-private partnerships in infrastructure: Indonesia's perspective," Eng. Constr. Archit. Manag., vol. 21, no. 4, pp. 383-402, 2014.

[12] M. Akhtar, "Strategic performance management system in uncertain business environment: An empirical study of the Indian oil industry," Bus. Process Manag. J., vol. 24, no. 4, pp. 923-942, 2018.

[13] M. A. Camilleri, "The marketing environment," in Travel Marketing, Tourism Economics and the Airline Product,
Springer, 2018, pp. 51-68

[14] K. Lee, Y. Park, and D. Lee, "Measuring efficiency and ICT ecosystem impact: Hardware vs. software industry," Telecomm. Policy, vol. 42, no. 2, pp. 107-115, 2017.

[15] J. Miler and K. Kaidy, "Problems and Solutions of Software Design in Scrum Projects," in 2018 Federated Conference on Computer Science and Information Systems (FedCSIS), 2018, pp. 975-978.

[16] L. Valverde, M. M. da Silva, and M. R. Gonçalves, "CMMI-DEV v1. 3 Reference Model in ArchiMate," in OTM Confederated International Conferences" On the Move to Meaningful Internet Systems", 2018, pp. 191208.

[17] C. E. Helfat, Dynamic capabilities: understanding strategic change in organizations. Blackwell Publ., 2010.

[18] S. Mclaughlin, "Dynamic capabilities: Taking an emerging technology perspective," Int. J. Manuf. Technol. Manag., vol. 31, p. 62, 2017

[19] M. R. Ayyagari and I. Atoum, "CMMI-DEV Implementation Simplified:A Spiral Software Model," Int. J. Adv. Comput. Sci. Appl., vol. 10, no. 4, pp. 445$450,2019$.

[20] D. J. Teece, "Business models and dynamic capabilities," Long Range Plann., vol. 51, no. 1, pp. 40-49, 2018.

[21] A. . Fallis et al., Dynamic Capabilities Understanding Strategic Change In Organizations, vol. 53, no. August. 2009.

[22] G. Ludwig and J. Pemberton, "A managerial perspective of dynamic capabilities in emerging markets: The case of the Russian steel industry," J. East Eur. Manag. Stud., pp. 215-236, 2011

[23] [23] G. A. Ortiz, M. E. M. Trujillo, H. Oktaba, and E. R. Hernandez, "Integrating agile methods into a level 5 cmmi-dev organization: a case study," IEEE Lat. Am. Trans., vol. 14, no. 3, pp. 1440-1446, 2016.

[24] A. L. Peres and S. L. Meira, "Towards a framework that promotes integration between the UX design and SCRUM, aligned to CMMI," in 2015 10th Iberian Conference on Information Systems and Technologies (CISTI), 2015, pp. 1-4.

[25] M. R. Ayyagari, "A Framework for Analytical CRM Assessments Challenges and Recommendations," Int. J. Bus. Soc. Sci., vol. 10, no. 5, p. [to appear], 2019.

[26] M. R. Ayyagari, "Integrating Association Rules with Decision Trees in ObjectRelational Databases," Int. J. Comput. Trends Technol., vol. 67, no. 3, pp. 102-108, 2019.

[27] M. R. Ayyagari, "iScrum: Effective Innovation Steering using Scrum Methodology,” Int. J. Comput. Appl., vol. 178, no. 10, pp. 8-13, May 2019.

[28] S. Mahmoodi, U. Durak, T. Gerlach, S. Hartmann, and A D'Ambrogio, "Extending the CMMI Engineering Process Areas for Simulation Systems Engineering," in Simulation Science, 2017, pp. 193-207.

[29] J. Brooke, "SUS-A quick and dirty usability scale," Usability Eval. Ind., vol. 189, no. 194, pp. 4-7, 1996. 